\title{
Scattering parameters measurements with the microwave transmittance technique using a microstrip patch antennas, as non-invasive tool for determination of soil moisture
}

\author{
Paulo Sergio de Paula Herrmann ${ }^{1, *}$, Felipe Nieves Marques Porto ${ }^{2}$ and Viktor Sydoruk ${ }^{3}$ \\ 1 Embrapa Instrumentation, São Carlos (SP), Brazil; paulo.herrmann@embrapa.br \\ 2 Maastricht University, Maastricht, Netherlands; porto.felipe94@gmail.com \\ 3 Forschungszentrum Jülich / IBG-2: Plant Sciences, Jülich, Germany; v.sydoruk@fz-juelich.de \\ * Correspondence: paulo.herrmann@embrapa.br; Tel.: +55-16-21072911
}

\begin{abstract}
Interactions of soil moisture with plant root systems are very important for plant growth. For non-invasive determination of volumetric soil moisture in a rhizobox, a microwave system based on transmittance of electromagnetic waves in the microwave frequency range was developed using microstrip patch antennas. Vector Network Analyzers (VNAs) were used to measure the S-parameters at frequency ranges close to $5 \mathrm{GHz}$. A transmission system with microstrip patch antennas was developed. The result of this attenuation is in the frequency domain. The antennae were designed as resonant microstrip antennae. The antennae were placed on both sides of a rhizobox, which allowed non-invasive measuring soil moisture in the box. The attenuation $\left(\mathrm{S}_{21}(\mathrm{~dB})\right)$ was used to measure the effect of temperature, and different types of soil; as well as sensitivity, reproducibility and repeatability of the system. In this work we present quantitative results of soil moisture in rhizobox. The microwave technique, using microstrip patch antennas, is a reliable and accurate system, and showed very promising potential applications for rhizobox-based investigations of root performance.
\end{abstract}

Keywords: microwave technique; transmittance; soil moisture; microstrip patch antennas; rhizobox; roots; plant phenotyping

\section{Introduction}

New tools or approaches are considered important to investigate and evaluate soil-water-plant interactions in the high-throughput plant phenotyping investigations [1]. A central parameter for determining root system response to water availability is that water is usually not homogeneously distributed in the soil and the heterogeneity significantly increases when drought stress occurs. Thus the development of non-invasive instruments and sensors to measure soil moisture distribution would open up new approaches to investigate plant strategies to deal with low water content or, in particular, heterogeneities in water availability of soils during periods of drought cycles.

Electromagnetic soil water content sensors are now widely accepted for soil water content determination because these sensors allow continuous, fast, stable, and nondestructive sensing of the spatial-temporal dynamics of soil water content at the lab and field scale [2].

From the electromagnetic point of view, the soil-plant-water set is considered a mixture of four dielectric compositions consisting of air, soil volume, bound water and free water, and roots. A water molecule attached to the soil interacts with an incident electromagnetic wave different from the free water molecule, thereby exhibiting a dielectric dispersion spectrum which is very different 
from free water. The dielectric constants in the complex form of free and bound water are functions of the electromagnetic frequency $(\mathrm{f})$, the physical temperature $(\mathrm{T})$ and the salinity $(\mathrm{S})$.

The dielectric properties of the wet soil are characterized by frequency dependence as a function of dielectric constant response. In a soil-plant-water systems the $\varepsilon_{\mathrm{r}}$ values for the soil are typically between 3 and 8 . In free water, also known as bulk water, the values are around 79 at 20 ${ }^{\circ} \mathrm{C}$, and for the roots of a plant they oscillate between 42 and 56 . The volumetric water contents of the roots samples vary linearly with the volume. The $\varepsilon_{\mathrm{r}}$ of the air is equal to 1 . In this way relatively small amounts of free water in the soil will greatly affect its electromagnetic properties (high degree of polarization under an external electrical field) [3, 4].

For non-invasive determination of volumetric soil moisture $(\theta \mathrm{V})$ a microwave system based on transmittance of electromagnetic waves in the frequency range close to $5.0 \mathrm{GHz}$ was developed using microstrip patch antennae. The antennae were placed on both sides of a rhizobox. The evaluation is made using scattering parameters (known as S-parameters) describing dispersion and dielectric properties of a soil-water. Figure 1(a) illustrates the basic principle of the electromagnetic wave (EM) interactions with the matter. A block diagram of the system that was developed to conduct this experiment can be seen in the figure 1(b). Calibration curves for four porous media are presented for two soils, the Nullerde - Einheitserde Typ 0 - Einheitserde- und Humuswerke, a peatsand-pumice substrate - Dachstaudensubstrat SoMi 513 (Kaktus soil), and Cerrado soil (tropical soil); and one for glass beads. The results presented in this work show a potential of using microwave transmittance technique and microstrip patch antenna for development of a new noninvasive determination of volumetric soil moisture $(\theta \mathrm{V})$ which can possibly be applied to the better understanding of root growth.

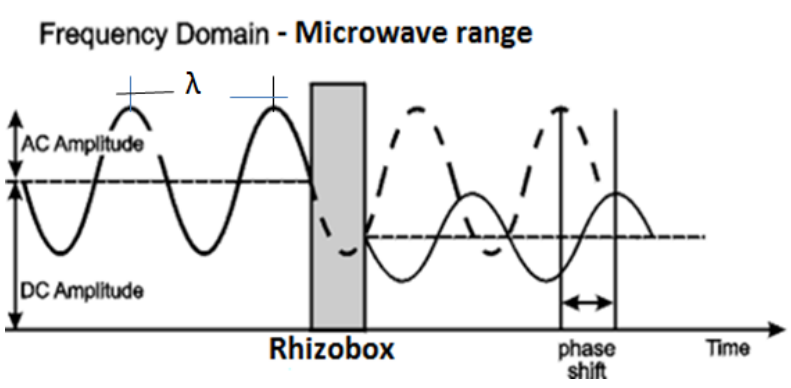

(a)

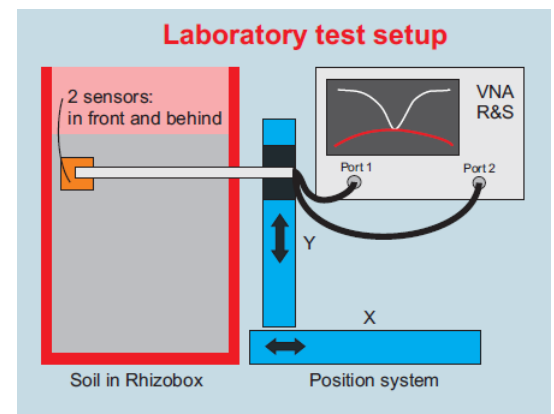

(b)

Figure 1. Diagram with basic principle of the system developed for this investigation. (Attenuation and phase shift) (Modified from [5]) (a). The block diagram of the system developed to measure $S_{21}(\mathrm{~dB})$ of the soil moisture in the rhizobox, using Vector Network Analyzer, in the microwave range (4.6 $\mathrm{GHz}$ to $5.0 \mathrm{GHz})(\mathbf{b})$.

\section{Materials and Methods}

\subsection{Vector Network Analyzer (VNA)}

The antennas are connected to the Vector Network Analyzer (VNA) (ZNB 8, Rohde \& Schwarz) which is generally used to generate and measure radio frequency/microwave signals [6]. Some features about the equipment used: Frequency range from $9 \mathrm{kHz}$ up to $40 \mathrm{GHz}$; Wide dynamic range of up to $140 \mathrm{~dB}$ and High temperature stability $0.01 \mathrm{~dB} /{ }^{\circ} \mathrm{C}$. Using VNA were measured scattering parameters (S-parameters $\left(\mathrm{S}_{21}(\mathrm{~dB})\right)$ in a frequency range from $4.6 \mathrm{GHz}$ to 5.0 $\mathrm{GHz}$ to characterize transmission of microwaves through a soil with a resolution of $6 \times 10^{-3} \mathrm{~dB}$.

The S-parameters describe how the system modifies a signal that is transmitted or reflected in forward or reverse direction [6]. For this experiment the value of $S_{21}(\mathrm{~dB})$ was used due the interaction of the microwave wave with our system (air - plexiglass (rhizobox) - soil - water), named in the figure 2 device under test (DUT). These parameters are considered the basic measured 
quantities of a network analyzer. In figure 1 there is a representation of the basic principle of sparameters for a 2-port measurement the signal flow.

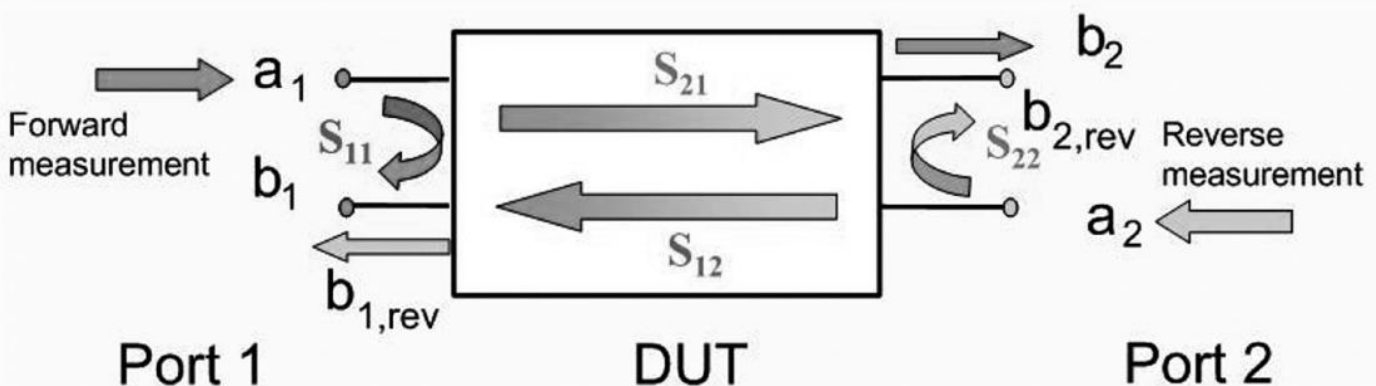

Figure 2 - The block diagram of the S-parameter basic principle used with our Vector Network Analyzer (VNA), ZNB 8, Rohde \& Schwarz (A) [6]

The equations used to obtain $S_{21}$ (equation (1)) and $S_{21}(\mathrm{~dB})$ (equation (2)) the following [6]:

And

$$
S_{21}=\frac{b_{2}}{a_{1}}=\frac{V \text { going out of port } 2}{V \text { coming into port } 1}, \text { when } a_{2}=0
$$

$$
S_{21}(d B)=-20 * \log \left|S_{21}\right|(d B)
$$

\subsection{Design of Microstrip Patch Antenna}

The antennae were designed as $\lambda / 2$-resonant microstrip antennae [7] and executed on a circuit board with a $1.5 \mathrm{~mm}$ thickness and a dielectric constant $\left(\varepsilon_{\mathrm{r}, \mathrm{sub}}\right.$ of 4.4$)$. Each antenna was $15.7 \mathrm{~mm}$ wide and $15.4 \mathrm{~mm}$ long. The total size is $25.0 \times 25.0 \times 1.5 \mathrm{~mm}^{3}$. Such a design allows working at frequencies close to $4.8 \mathrm{GHz}$. Figure 3 illustrates the microstrip antenna design to microwave range [8].

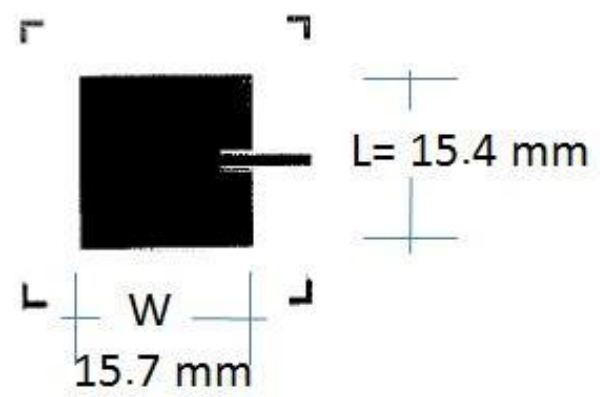

Figure 3.The mask used to develop the microstrip antenna on to circuit board

\subsection{Details of Rhizobox used:}

The rhizoboxes were made out of PVC and Plexiglas $(\varepsilon r \sim 2.6)$ and PVC $(\varepsilon r \sim 2.9)$ with walls of about $5.0 \mathrm{~mm}$ in thickness, a length of $315.0 \mathrm{~mm}$ and a width of $200.0 \mathrm{~mm}$. The internal space for the porous media samples is $20.0 \mathrm{~mm}$.

\subsection{Measurement of reproducibility and repeatability (Dielectric Constant vs Attenuation):}

The two chemical solutions used were 1,4-Dioxane $\left(\mathrm{C}_{4} \mathrm{H}_{8} \mathrm{O}_{2}\right)$ and 2-Isopropoxyethanol $\left(\left(\mathrm{CH}_{3}\right)_{2} \mathrm{CHOCH}_{2} \mathrm{CH}_{2} \mathrm{OH}\right)$, abbreviated as $\mathrm{i}-\mathrm{C}_{3} \mathrm{E}_{1}$. The objective was to make an "ideal solution" by combining water $\left(\varepsilon_{w}=79(1.2 \mathrm{GHz})\right)$ and another liquid fully miscible in water. Dioxane is a strong solvent with a low flash point and a high volatility. 
The mixtures, values and relative complex dielectric permittivity parameters are derived from [9]. The real and imaginary part of the complex dielectric permittivity of the reference liquids were described by the Cole-Cole model [10]. The model can be seen in the equation (1):

$$
\varepsilon=\varepsilon_{\infty}+\frac{\left(\varepsilon_{S}-\varepsilon_{\infty}\right)}{1+(j \omega \tau)^{1-\alpha}}-j \frac{\sigma}{\omega \varepsilon_{0}}
$$

The $\varepsilon$ represents the complex dielectric permittivity, while $\varepsilon s[-]$ and $\varepsilon \infty[-]$ are the permittivity at frequencies $(\mathrm{Hz})$ much lower and much higher than the relaxation frequency $\mathrm{f}_{\text {rel }}[\mathrm{Hz}$ ], respectively, $\alpha[-]$ is the dispersion factor for the relaxation time $(0<\alpha<1), \sigma\left[S^{*} \mathrm{~m}^{-1}\right]$ is the electrical conductivity and $\varepsilon_{0}$ is the free space permittivity.

The concentrations of the liquids were created as is shown in the following table 1, based in Rosenbaum and collaborators [9].

Table 1: The volume fraction of the liquids as well the dielectric constant and a relation with soil moisture.

\begin{tabular}{c|c|c|c|c|c}
\hline Reference & Medium & \multicolumn{2}{|c|}{ Volume Fraction } & $\varepsilon_{\mathbf{s}} \approx \varepsilon_{\text {ref }}$ & $\theta_{\text {eq }}$ \\
\hline Liquid & & $\begin{array}{c}\text { Dioxan } \\
\text { e/ i-C }\end{array}$ & $\begin{array}{c}\text { Deionized } \\
\text { Water }\end{array}$ & & \\
\hline & & {$[-]$} & {$[-]$} & {$[-]$} & {$\left[\mathrm{m}^{3} \mathrm{~m}^{-3}\right]$} \\
\hline M1 & Dioxane & 0.90 & 0.10 & 6.65 & 0.117 \\
M2 & i-C $E_{1}$ & 1.00 & 0.00 & 11.95 & 0.228 \\
M3 & i-C $E_{1}$ & 0.92 & 0.08 & 18.14 & 0.331 \\
M4 & i-C $E_{1}$ & 0.86 & 0.14 & 22.15 & 0.388 \\
M5 & i-C $E_{1}$ & 0.80 & 0.20 & 26.26 & 0.441 \\
M6 & i-C $E_{1}$ & 0.73 & 0.27 & 31.38 & 0.502 \\
M7 & i-C $E_{3}$ & 0.68 & 0.32 & 34.82 & 0.540 \\
\hline
\end{tabular}

\subsection{Calibration Curve:}

Each sample was prepared to have the same bulk density (@ss) of a dry soil and its different volumetric soil moisture, $\theta \mathrm{V}(\%)$. Three different porous media (PM) were used: Nullerde (Einheitserde Typ 0, Einheitserde- und Humuswerke Gebr. Patzer GmbH \& Co. KG), peat-sandpumice substrate (Dachstaudensubstrat SoMi 513, Hawita GmbH, Vechta, Germany ((Kaktus soil)), all of the substrate soils are considered temperate soil and glass beads (particles size $\sim 0.25 \mathrm{~mm}$ ). The soil used in these experiments was the dystrophic Red Latosol/Oxisol (Tropical Cerrado soil Brazil ( $\left.\varrho_{s s}=1.19 \mathrm{~g} / \mathrm{cm}^{3}\right)$ ). The @ss, during the experiments were about $0.28 \mathrm{~g} / \mathrm{cm}^{3}, 0.59 \mathrm{~g} / \mathrm{cm}^{3}$ and 1.54 $\mathrm{g} / \mathrm{cm}^{3}$, respectively. The experiments were made under laboratory conditions at temperature of about $25.0 \pm 0.5^{\circ} \mathrm{C}$ and relative humidity of $\sim 30.0 \%$. Additionally, the influence of temperature for Nullerde soil (considered nutrient-deficient substrates) was measured under climate controlled environment at temperature range from $13.0 \pm 0.5^{\circ} \mathrm{C}$ to $39.0 \pm 0.5^{\circ} \mathrm{C}$.

The volumetric moisture was taken because electromagnetically the dielectric constant of the soil-water mixture is a function of the water volume fraction in the mixture [11].

\begin{tabular}{lcccccccc}
\multicolumn{1}{c}{ Samples } & $\begin{array}{c}\text { Clay } \\
\%\end{array}$ & $\begin{array}{c}\text { Sand } \\
\%\end{array}$ & $\begin{array}{c}\text { Silt } \\
\%\end{array}$ & $\begin{array}{c}\mathrm{N} \\
\%\end{array}$ & $\begin{array}{c}\mathrm{C} \\
\%\end{array}$ & $\mathrm{C} / \mathrm{N}$ & $\begin{array}{c}\mathrm{Fe} \\
\mathrm{mg} / \mathrm{g}\end{array}$ & $\begin{array}{c}\rangle_{\mathrm{ss}} \\
\mathrm{g} / \mathrm{cm}^{3}\end{array}$ \\
\hline $\begin{array}{l}\text { Nullerde (Einheitserde } \\
\begin{array}{l}\text { Typ 0) } \\
\text { Dachstau den substrat }\end{array}\end{array}$ & 35.0 & - & - & 0.45 & 22.1 & 48.9 & 30.5 & 0.28 \\
$\begin{array}{l}\text { Somi 513 (Kaktus soil) } \\
\text { Dystrophic Red Latosol } \\
\text { (Oxisol) - Cerrado Soil }\end{array}$ & 19.1 & - & 23.1 & 0.21 & 12.5 & 43.0 & 183 & 0.59 \\
(Go / BR) & 58.2 & 18.4 & 23.4 & - & 18.5 & - & 120 & 1.19
\end{tabular}


Glass Beads* $(210-250\lceil\mathrm{~m})$

1.54

*Glass Beads chemical composition (by weight): Silica $\left(\mathrm{SiO}_{2}\right)=66-75 \%$; Aluminun Oxide $\left(\mathrm{Al}_{2} \mathrm{O}_{3}\right)=0-5 \%$; Calcium Oxide $(\mathrm{CaO})=6-15 \%$; Magnesium Oxide $(\mathrm{MgO})=1-5 \%$; Sodium Oxide $(\mathrm{Na} 2 \mathrm{O})=10-20 \%$ and Iron Oxide $\left(\mathrm{Fe}_{2} \mathrm{O}_{3}\right)=<0.8 \%$

The equation 2 can be used to calculated the volumetric soil moisture $(\theta \mathrm{V}(\%))$ :

$$
\theta V(\%)=\left(\left(\frac{V_{H_{2} O}}{M_{d s}}\right) \times \rho_{s s}\right) \times 100
$$

where: $V_{\text {H2O }}$ is the volume of the water $\left(\mathrm{cm}^{3}\right)$; $\mathrm{Mds}$ is the weight of the dry soil $(\mathrm{g})$; Qss is the dry soil density $\left(\mathrm{g}^{*} \mathrm{~cm}^{-3}\right)$

\section{Results and Discussion}

\subsection{Evaluation of reproducibility and repeatability of the system developed}

The aim of this experiment was to correlate attenuation values received from the rhizobox with the concentration of chemical organic solution placed for analysis. This experiment aimed to correlated the dielectric permittivity constant of certain concentrations of organic chemical solutions (in this case mainly 2-isopropoxyalcohol) with the microwave attenuation values. The results clearly show a relation between the two variables - mainly which as the dielectric permittivity increases, so does the attenuation. The figure 4 is demonstrating the percentage of reliability of reproducibility and repeatability shows that this same experiment should theoretically be possible to perform in any circumstance, resulting in the same values.

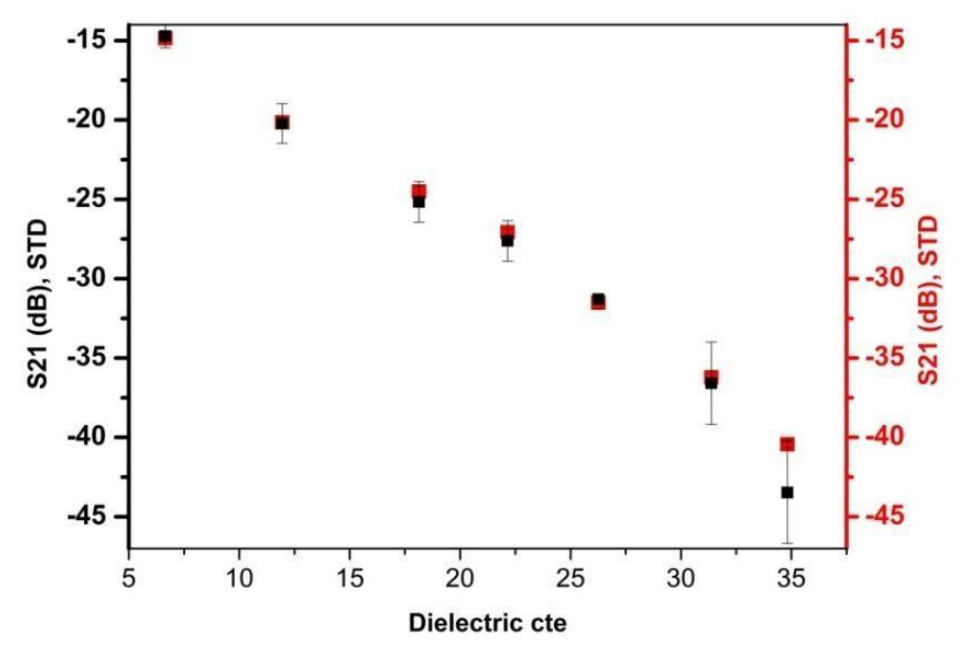

Figure 4. The repeatability and reproducibility of the system developed were calculated. The measurement was carrying out three times to each dot $(n=3)$. The red dots represent the reproducibility (98.9\%) averages and the black dots represent the repeatability $(93.0 \%)$ averages.

\subsection{The influence of temperature during the measurement of volumetric soil moisture $(\theta V(\%))$.}

The influence of temperature $\left({ }^{\circ} \mathrm{C}\right)$ is an important parameter in the measurement of soil moisture. Figure 5 shows the influence of temperature during the measurement of volumetric soil moisture of the Null Erde sample (soil bulk density (@ss) $=0.28 \mathrm{~g} / \mathrm{cm}^{3}$ ). The situation is dramatically changed when PM has a high amount of water. The $\Delta \mathrm{T}\left({ }^{\circ} \mathrm{C}\right)$ was equal $26.0 \pm 0.5{ }^{\circ} \mathrm{C}$ and the maximum variation of $S_{21}(\mathrm{~dB})$ was $35.3 \%$ to $\theta \mathrm{V}(\%)=45.0 \%$. 


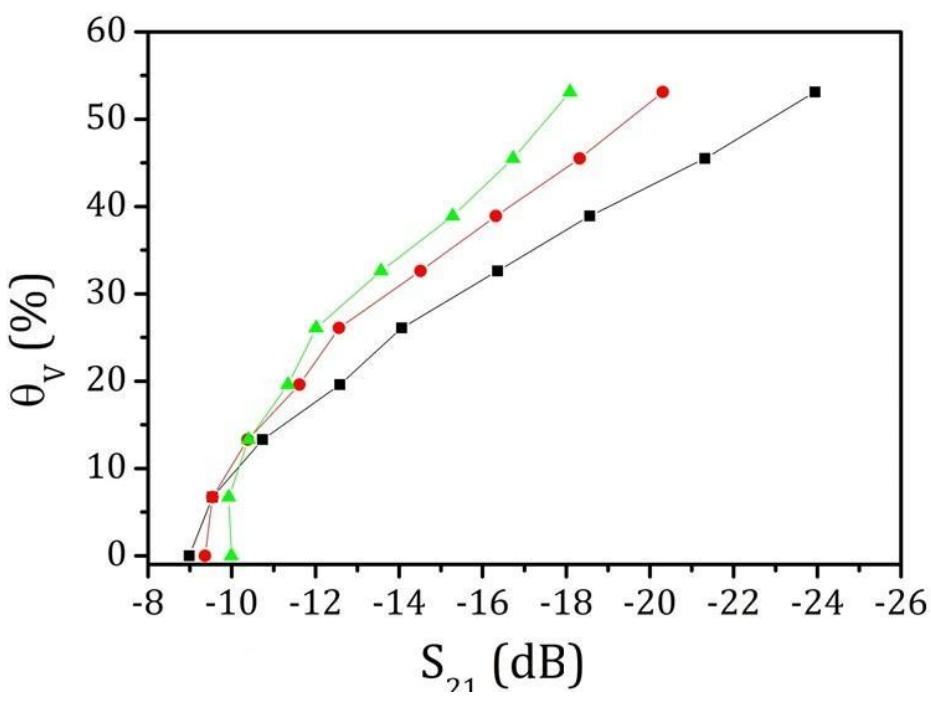

Figure 5. The influence of temperature in the measurement of $\theta \mathrm{V}(\%)$ using the attenuation $\left(\mathrm{S}_{21}(\mathrm{~dB})\right)$. The porous media used was Null Erde and the temperature set up to this experiment was $13.0 \pm 0.5(-\mathbf{m}-)$, $26 \pm 0.5^{\circ} \mathrm{C}(-\bullet-)$ to $39.0 \pm 0.5^{\circ} \mathrm{C}(-\boldsymbol{\Delta}-)$.

The experiment was conducted using the climate controlled environment to varied temperature from $13{ }^{\circ} \mathrm{C}$ to $39{ }^{\circ} \mathrm{C}$ in increment of $13^{\circ} \mathrm{C}$. In $0.0 \%$ of the volumetric soil moisture $(\theta \mathrm{V}$ $(\%))$ the variation of $\mathrm{S}_{21}(\mathrm{~dB})$ was $5.4 \%$, the lowest influence of temperature occurred with $\theta \mathrm{V}(\%)$ of $14.5 \%$, with an error of $-1.9 \%$. The higher value was of $14.2 \%$ in temperature, with $52.5 \%$ of $\theta \mathrm{V}$ (\%). Indicating increased efficiency of microwave absorption with the volumetric soil moisture at higher temperatures.

In figure 5 it is possible to observe two distinct behaviors in the error, below and above $14.5 \%$ of $\theta \mathrm{V}(\%)$. The error of the soil moisture measurements under influence of temperature is not to be despised. This indicates a temperature effect on soil dielectric permittivity as soil water content increases. Gong and collaborators in 2003 [12] shows in his paper the measurement error changes with temperature at different soil moisture levels. Basically, the same features were observed in our results presented in the figure 5 .

\subsection{The calibration curve and modeling of volumetric soil moisture $(\theta V(\%))$ in function of $S_{21}(d B)$.}

Different calibration curves are needed for different PM. Calibration curves were obtained by measuring $\mathrm{S}_{21}$-parameter $(\mathrm{dB})$, which reflects transmission of EM waves. Measuring the attenuation of transmitted signal we obtained clear dependence of $\theta \mathrm{V}(\%)$ on $S_{21}(\mathrm{~dB})$. The dependence tends to be comparable for different PM when it is relatively dry, below $20.0 \%$ of $\theta \mathrm{V}(\%)$, and has a small dependence of bulk density, as well the soil physical and chemical properties of each PM, mainly the typical tropical soil (Cerrado soil).

The curve obtained to four (04) samples (Cerrado Soil, Null Erde, Kaktus Soil and Glass Beads) is shown in the figure 6 and the equation the table (2):

Table 2: Table with equation used to modeling the calibration to each sample.

\begin{tabular}{|c|c|c|c|}
\hline & Samples & Equation & $\mathbf{R}^{2}$ \\
\hline 1 & $\begin{array}{c}\text { Cerrado Soil } \\
\text { @ss }=1,19 \mathrm{~g}^{*} \mathrm{~cm}^{-3}\end{array}$ & $\Theta_{\mathrm{v}}(\%)=-0.00258^{*} \mathrm{~S}_{21}(\mathrm{~dB})^{3}+0.07924^{*} \mathrm{~S}_{21}(\mathrm{~dB})^{2}+0.27515^{*} \mathrm{~S}_{21}(\mathrm{~dB})-4.72555$ & 0.9834 \\
\hline 2 & $\begin{array}{c}\text { Null Erde } \\
\mathrm{Qss}=0,28 \mathrm{~g}^{*} \mathrm{~cm}^{-3}\end{array}$ & $\Theta_{v}(\%)=-0.18679 * S_{21}(d B)^{3}-7.79899 * S_{21}(d B)^{2}-112.0218^{*} S_{21}(d B)-524.374$ & 0.9804 \\
\hline 3 & $\begin{array}{c}\text { Kaktus Soil } \\
\text { @ss }=0,59 \mathrm{~g}^{*} \mathrm{~cm}^{-3}\end{array}$ & $\Theta_{\mathrm{v}}(\%)=0.1555^{*} \mathrm{~S}_{21}(\mathrm{~dB})^{3}+4.16601 * \mathrm{~S}_{21}(\mathrm{~dB})^{2}+29.24777^{*} \mathrm{~S}_{21}(\mathrm{~dB})+42.96299$ & 0.9725 \\
\hline 4 & $\begin{array}{c}\text { Glass Beads } \\
\varrho s s=1,54 \mathrm{~g}^{*} \mathrm{~cm}^{-3}\end{array}$ & $\Theta_{v}(\%)=-0.19723^{*} S_{21}(d B)^{2}-8.78181^{*} S_{21}(d B)-52.87515$ & 0.9923 \\
\hline
\end{tabular}




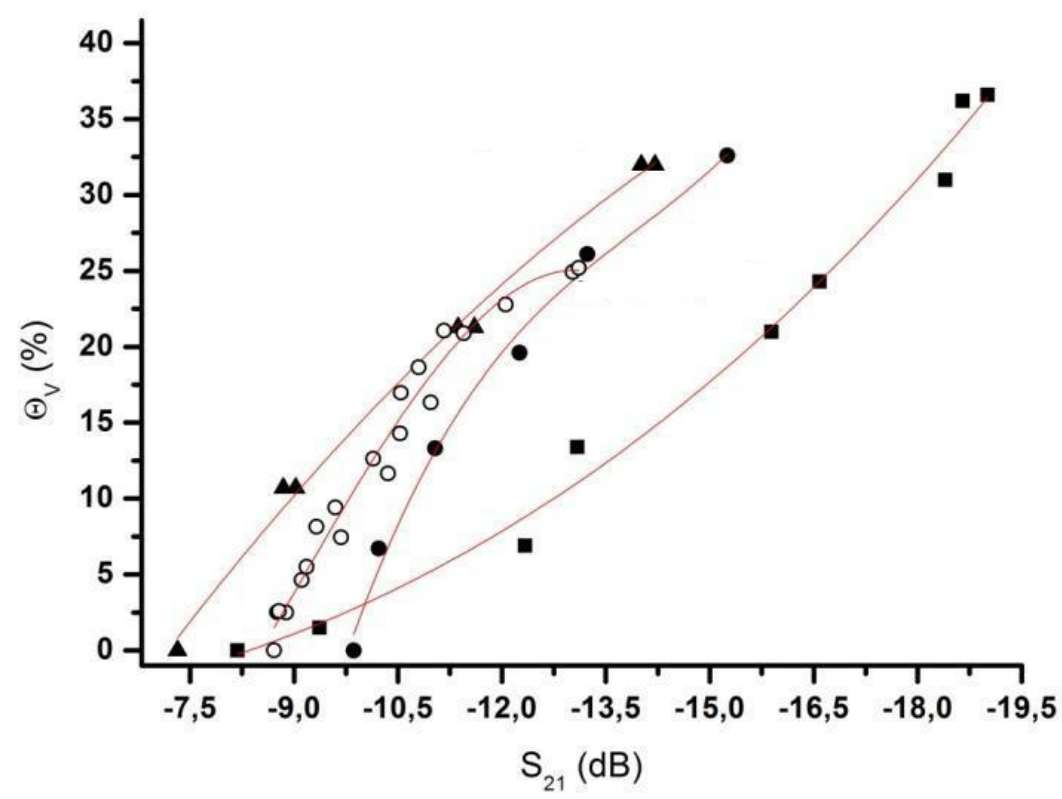

Figure 6. Relation between the $S_{21}(\mathrm{~dB})$ measured with the system developed and the volumetric soil moisture $(\theta \mathrm{V}(\%))$ determined and calculated by second and third order polynomial equation. The equations were presented in the table 2. The four (04) samples used are: Cerrado Soil (a), Null Erde $(\bullet)$, Kaktus Soil (०) and Glass Beads $(\boldsymbol{\Delta})$. The experiment was carrying out in the lab air condition ( $\mathrm{T}$ $\sim 25.0 \pm 0.5^{\circ} \mathrm{C}$ and $\left.\mathrm{RH}(\%) \sim 30 \%\right)$.

In the previous experiment, as shown in figure 4, it was observed for the Null Erde soil that the influence of the temperature is minimal for volumetric soil moisture around $14.5 \%$. In this way, this value was kept to the soil moisture to evaluate the influence of different PM and its bulk density (@ss) in the measurement of S parameter. Figure 6 shows the effect of the distinct PM in the calibration curve. The range used to this experiment were PM with distinct bulk density $0.28 \mathrm{~g} / \mathrm{cm}^{3}$ (organic substrate), $1.19 \mathrm{~g}^{*} \mathrm{~cm}^{-3}$ (clay), $0.59 \mathrm{~g}^{*} \mathrm{~cm}^{-3}$ (silt) and $1.54 \mathrm{~g}^{*} \mathrm{~cm}^{-3}$ (inorganic PM). The attenuation $\left(\mathrm{S}_{21}\right)$ was approximately $-4.0 \mathrm{~dB}$. By showing that physical-chemistry characteristics, has to be account in the measurements of $\theta \mathrm{V}(\%)$, in this frequency $(\mathrm{Hz})$. With the use of time domain reflectometry (TDR) equipment, in the frequency around $1.2 \mathrm{GHz}$, Gong and collaborators [12] present the effect of soil density.

Figure 7 shows preliminary results of the measurement of $\overline{S_{21}}(\mathrm{~dB})$ attenuation of volumetric soil moisture in the rhizobox, during the time (16 days: $21 \mathrm{hr}: 17 \mathrm{~min})$ and it is possible to observe how the values change of the of $S_{21}(\mathrm{~dB})$ and STD $S_{21}(\mathrm{~dB})$ with volumetric soil moisture, during time elapsed, inside the rhizobox. The sample is Kaktus soil with maize. The experiment was organized to observe the attenuation of soil moisture during the time of the root growth. The measurement was taken in laboratory conditions $\left(\mathrm{T}=24.3 \pm 1.1^{\circ} \mathrm{C}\right.$ and $\left.\mathrm{RU}=62.8 \pm 5.0 \%\right)$ during the morning, the afternoon, the night and dawn to measure the behavior of the water. To conduct this experiment there were set up 3 distinct steps, as following: Step 1) Start condition using just soil moisture inside the rhizobox; Step 2) Included two maize seeds into soil and Step 3) After 12 days : $09 \mathrm{hr}$ : $11 \mathrm{~min} 30 \mathrm{ml}$ of DI water was added.

Initially, the experiment was fed with water in step 1 and step 2. Subsequently the plant was left to grow and the soil was left to dry out for 150 hours, with measurements taken every 6 hours (morning - 9:00am; afternoon - 3:00 pm; night - 9:00pm and dawn - 3:00am). The quantitative data were obtained from a specific area $\left(\mathrm{A}_{\mathrm{qd}}=168\left(\mathrm{~cm}^{2}\right)\right)$, around $48.0 \%$ of the total area of the rhizobox with soil. To calculate the $\overline{S_{21}}(d B)=\mathrm{S}_{21}(\mathrm{~dB}) \pm \operatorname{Std}\left(\mathrm{S}_{21}(\mathrm{~dB})\right)$, 1173 data points were used from the matrix. 
The soil moisture decreased with time, from $\theta \mathrm{V}(\%)=34.5 \%$ to $27,2 \%$. The range of the data collected was after 01 day: 15 hour: 17 min until 12 days: 09 hours: 11 min the experiment running, and are showing the increase of attenuation measuring the $S_{21}(d B)$ and std $S_{21}(d B)$ table 3 is presents a specific region from figure 6 , that shows an inversion behavior of average S21 (dB) and using the absolute value of the std $S_{21}(\mathrm{~dB})$.

Table 3: Values obtained from specific region of the figure 6

\begin{tabular}{cccc} 
& Time (DD:HH:mm) & $\mathrm{S}_{21}(\mathrm{~dB}) / \theta \mathrm{V}(\%)^{1}$ & ${\text { std } \mathrm{S}_{21}(\mathrm{~dB})}$ \\
Start & $03: 21: 10$ & $-15.18 / 34.5$ & 1.75 \\
End & $06: 20: 50:$ & $-14.39 / 27.2$ & 2.03 \\
\hline
\end{tabular}

${ }^{1} \theta \mathrm{V}(\%)$ was calculate using the equation (3) Kaktus soil, from the table 2.

As the dielectric constant of the root $\left(42<\varepsilon r<56\left(f_{0}=1.2 \mathrm{GHz}\right)\right)$ is much higher than dry soil $(3<\varepsilon r<8)$ and near of the water $(\varepsilon r \sim 79)$ [4], it is possible to hypothesize that it could be a factori influencing root growth, mainly with increasing of the root density, in the region that the measurements were taken. To propose this approach we considered the soil bulk density is low (@ss $0.59 \mathrm{~g} / \mathrm{cm}^{2}$ ); the discussion about application of three phase mixing model [13]; the hydraulic redistribution of water through roots maintain roots turgid, as was discussed by de Willigen and collaborators in his paper [14]; Bao et al., (2018) elaborates on the importance of the water around the root tip, and how it plays an important role in the establishment of root system architecture [15]. In the area analyzed, the root as well the fraction of water could occupy the higher amount of soil porosity and consequently the influence average of $S_{21}(\mathrm{~dB})$ and his standard deviation.

The experiment shown in figure 7 is considered a new opportunity to study phenotyping and the influence of the soil and water in the root and plant growth during through time.

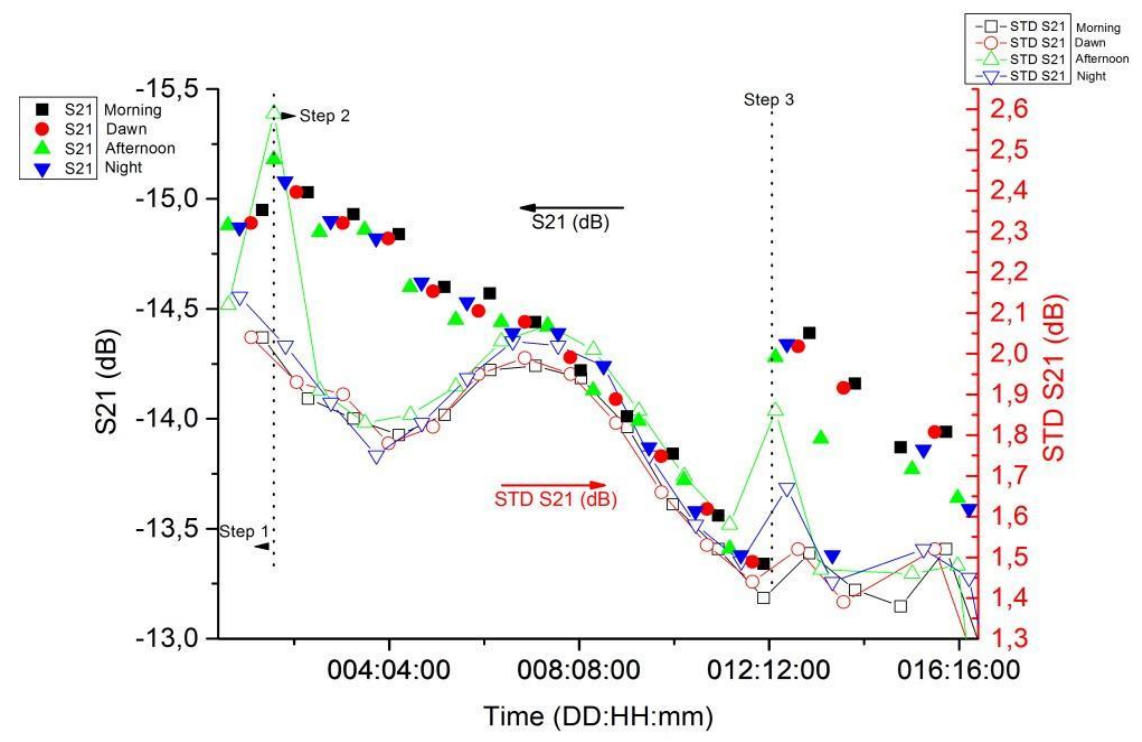

Figure 7. Results of the measurement of $\overline{S_{21}}(d B)$ attenuation of volumetric soil moisture in the rhizobox, during the time (16 days:21 hr:17 $\mathrm{min}$ ) and a calculation of standard deviation (STD $\mathrm{S}_{21}(\mathrm{~dB})$ ). The sample is a Kaktus soil with maize. The experiment was organized in three steps to measure the attenuation of soil moisture during the time of the roots growth. The measurement was taken in the lab conditions $\left(\mathrm{T}=24.3 \pm 1.1{ }^{\circ} \mathrm{C}\right.$ and $\mathrm{RH}=62.8 \pm 5.0 \%$ ) during the dawn (3:00 am), the morning (9:00 $\mathrm{am})$, the afternoon (3:00 pm) and the night (9:00 pm).

\section{Conclusions}

From the measured results it is possible to conclude that the developed non-invasive microwave method, using microstrip antennae, is an innovative sensing method to measure the 
water status in rhizobox filled with soil. The system that was developed did not using invasive rods - like TDR technique normally use in the measure of soil moisture - which could have influence in the direction of root growth. A low power microwave non ionization radiation was used, with the frequency around $4.8 \mathrm{GHz}$ using attenuation measurements. The results presented in this work demonstrate that the system developed has high reproducibility $(98.9 \%)$ and good repeatability $(93.0 \%)$ to measure volumetric soil moisture $\theta \mathrm{V}(\%)$. The temperature has an influence in the measurement $\theta \mathrm{V}(\%)$. Since the temperature effect under the error of the measurements of volumetric soil moisture, a calibration curve requires the information of both soil temperature and soil water content. The effect of the distinct PM in the calibration curve $\left(\mathrm{S}_{21}(\mathrm{~dB}) \times \theta \mathrm{V}(\%)\right)$ were observe. This can be used to investigate the growth of plant roots together with soil physics properties. Such kind of approach gives an opportunity to apply it to study root / plant phenotyping and monitor non-invasive volumetric soil moisture distribution, using rhizobox. Further investigations are conducted with a development and use of $S$ parameters, automation and microstrip patch antenna arrays, which could help and improve the non-invasive evaluation of soilwater-roots investigations.

Acknowledgments: The Forschungszentrum Jülich (FZJ/Jülich) / IBG-2: Plant Science to the support and facilities, the Jülich Plant Phenotyping Center (JPPC), as well the Enabling Technologies group to good discussion and use of the laboratories.

Funding: This research was financially supported by Embrapa Labex Europe Program, Agropolis, Montpellier, France, number DZ002947.

Conflicts of Interest: The authors declare no conflict of interest. The funders had no role in the design of the study; in the collection, analyses, or interpretation of data; in the writing of the manuscript, and in the decision to publish the results.

\section{References}

1. Fiorani, F. and Schurr,. U.. Future Scenarios for Plant Phenotyping, Annual Review of Plant Biology, 2013, vol.64, pp.267 - 291, DOI: 10.1146/annurev-arplant-050312-120137.

2. Qu, W.; Bogena, H.R.; Huisman, J.A.; Vereecken, H. Calibration of a novel low-cost soil water content sensor based on a ring oscillator. Vadose Zone J., 2013, vol. 12, n. 2, DOI: 10.2136/vzj2012.0139.

3. Schmugge, T. J. and Jackson, T. J. Survey of methods for soil moisture determination, Water Resources Research, 1980, vol. 16, n. 6, pp. 961 - 979, DOI: 10.1029/WR016i006p00961.

4. Mojid, M. A. and Cho, H.. Evaluation of the time-domain reflectometry (TDR)-measured composite dielectric constant of root-mixed soils for estimating soil-water content and root density, Journal of Hydrology, 2004, vol. 295, pp. 263-275, DOI: 10.1016/j.jhydrol.2004.03.012.

5. Pellicer, A. and Bravo, M. d. C. Near-infrared spectroscopy: a methodology-focused review, Seminars in fetal \& neonatal medicine, 2011, vol. 16, Iss.: 1, pp. 42-49, DOI: 10.1016/j.siny.2010.05.003.

6. Measured Quantities. Available online: http://labrf.av.it.pt/Data/Manuais \& Tutoriais/40b - VNA ZVB20/CD/documents/Help Files/WebHelp ZVT/System Overview/Measurement Parameters/SParameters.htm (accessed on 20 November 2014).

7. Cataldo, A.; Monti, G.; De Benedetto, E.; Cannazza, G. and Tarricone, L.. A noninvasive resonance-based method for moisture content evaluation through microstrip antennas, IEEE Transactions on Instrumentation and Measurement, 2009, vol. 58, Iss.: 5, pp. 1420-1426, DOI: 10.1109/TIM.2009.2014513.

8. Paul, L. C.; Hosain, M. S.; Prio, M. H.; Morshed, M.; Sarkar, A. K.. The Effect of Changing Substrate Material and Thickness on the Performance of Inset Feed Microstrip Patch Antenna. American Journal of Networks and Communications, 2015, Vol. 4, No. 3, pp. 54-58, DOI: 10.11648/j.jnc.20150403.16.

9. Rosenbaum, U.; Huisman, J. A.; Vrba, J.; Vereecken, H.; Bogena, H. R. Correction of Temperature and Electrical Conductivity Effects on Dielectric Permittivity Measurements with ECH2O Sensors, Vadose Zone Journal, 2011, vol. 10, Iss.: 2, pp. 582-593, DOI: 10.2136/vzj2010.0083.

10. Cole, K. S.; Cole, R. H. Dispersion and Absorption in Dielectrics - I Alternating Current Characteristics, J. Chem. Phys., 1941, vol. 9, pp. 341-352, DOI: 10.1063/1.1750906. 
11. Hallikainen, M. T.; Ulaby F. T.; Dobson, M. C.; El-Rayes, M. A.; Wu, L.-K. Microwave Dielectric Behavior of Wet Soil-Part 1: Empirical Models and Experimental Observations, IEEE Transactions on Geoscience and Remote Sensing, 1985, vol. GE-23, Iss. 1, pp. 25-34, DOI: 10.1109/TGRS.1985.289497.

12. Gong, Y.; Cao, Q.; Zongjia Sun, Z.. The effects of soil bulk density, clay content and temperature on soil water content measurement using time-domain reflectometry, Hydrological Processes, 2003, vol. 17, pp. 3601-3614, DOI: 10.1002/hyp.1358.

13. Vaz, C. M. P.; Hopmans, J. W.; Macedo, A.; Bassoi, L. H.; Wildenschild, D.. Soil Water Retention Measurements Using a Combined Tensiometer-Coiled Time Domain Reflectometry Probe. Soil Sci. Soc. Am. J., 2002, vol. 66, pp. 1752-1759, DOI:10.2136/sssaj2002.1752.

14. de Willigen, P.; Heinen, M.; van Noordwijk, M.. Roots Partially in Contact with Soil: Analytical Solutions and Approximation in Models of Nutrient and Water Uptake, Vadose Zone J., 2017, vol. 17, n. 170060. pp. 1-16, DOI:10.2136/vzj2017.03.0060.

15. Bao, Y.; Aggarwal, P.; Robbins, N. E.; Sturrock, C. J.; Thompson, M. C.; Tan, H. Q.; Tham, C.; Duan, L.; Rodriguez, P. L.; Vernoux, T.; Mooney, S. J.; Bennett, M. J.; Dinneny, J. R.. Plant roots use a patterning mechanism to position lateral root branches toward available water, PNAS, 2014, vol. 111, no. 25, pp. 9319-9324, DOI: 10.1073/pnas.1400966111. 